\title{
MARCAS [BRANCAS] DO ESCRAVISMO NAS POLÍTICAS PÚBLICAS DE EDUCAÇÃO NO BRASIL CONTEMPORÂNEO
}

\author{
[WHITE] MARKS OF SLAVERY IN PUBLIC POLICYEDUCATION IN CONTEMPORARY BRAZIL \\ MARCAS [BLANCAS] DEL ESCLAVISMO EN LAS POLÍTICAS PÚBLICASDE EDUCACIÓN EN EL BRASIL \\ CONTEMPORÁNEO
}

ECKER, Daniel Dall'Igna 1

\section{RESUMO}

Este ensaio discorre acerca da construção do direito à educação no Brasil, evidenciando como a presença de pessoas [com pele branca] foram historicamente determinantes na elaboração das políticas de educação do Brasil contemporâneo. Para isso, analisa as Constituições Federais brasileiras (1824; 1891; 1934; 1937; 1946; 1967; 1988), em articulação com estudos sobre as especificidades sócio-históricas do país. Através dos materiais, explicita a presença da cor/raça [branca] na formulação das políticas de educação e aponta alguns dos possíveis efeitos dessa branquitude, no delineamento dos grupos raciais que acessaram a educação, enquanto direito, e como via de acesso ao poder.

Palavras-chave:Branquitude; Escravismo; Direito à educação; Constituição Federal; Brasil.

\section{ABSTRACT}

This essay discusses the construction of the right to education in Brazil, evidencing how the presence of people [with white skin] was historically determinant in the elaboration of education policies in contemporary Brazil. In order to do so, it analyzes the Brazilian Federal Constitutions $(1824,1891,1934,1937,1946,1967,1988)$ in articulation with studies on the socio-historical specificities of the country. Through the materials, it explains the presence of color/race [white] in the formulation of education policies and points out some of the possible effects of this whiteness: in the delineation of the racial groups that accessed education as a right, and as a way of access to power.

Keywords: Whiteness; Slavery; Right to education; Federal Constitution; Brazil.

\section{RESUMEN}

Este ensayo discurre acerca de la construcción del derecho a la educación en Brasil, evidenciando cómo la presencia de personas [con piel blanca] fueron históricamente determinantes en la elaboración de las políticas de educación del Brasil contemporáneo. Para ello, analiza las Constituciones Federales brasileñas (1824, 1891, 1934, 1937, 1946, 1967, 1988) en articulación con estudios sobre las especificidades socio históricas del país. A través de los materiales, explicó la presencia del color/raza [blanca] en la formulación de las políticas de educación y apunta algunos de los posibles efectos de esa branquitud: en el delineamiento de los grupos raciales que accedieron a la educación en cuanto derecho, y como vía de acceso al poder.

Palabras clave:blancura; la esclavitud; Derecho a la educación; Constituicion Federal; Brasil.

\footnotetext{
1 Universidade Federal do Rio Grande do Sul - UFRGS - Porto Alegre - Brasil
} 


\section{INTRODUÇÃO}

O acesso à educação no Brasil, por séculos, fora destinado com prioridade a uma pequena parcela da população, de forma seletiva e elitizada [majoritariamente de pele branca $^{2}$ e de religião católica], mantendo, por muito tempo, distante das práticas de Estado, a ideia de direito à educação. A noção de direito à educação foi adicionada [por brancos] na Constituição de 1934 e, mesmo assim, não produziu efeitos suficientes para garantir a produção de serviços públicos, universais e gratuitos, acessíveis a todos(as) naquele período (CURY, 2007). Mantendo-se como campo de disputas e de embates, ao longo do século XX, a educação foi incluída na Constituição de 1988, no Capítulo II - dos Direitos Sociais [por um presidente da Assembleia Nacional Constituinte de pele branca], como um dos fundamentos da República Federativa, no que se referia ao desenvolvimento de um Estado Democrático de Direito (BRASIL, 1988).

Sob o argumento de ser um direito público subjetivo, no nível fundamental, a educação, a partir dos anos 80, ganhou destaque nos argumentos e ações Estatais, como estratégia de inclusão social e, via Ministério da Educação [MEC] e seu Fundo Nacional de Desenvolvimento da Educação [FNDE], tornou possível a emergência de uma série de programas e políticas voltados a essa finalidade (BRASIL, 2015).A ideia de inclusão social pelas políticas públicas de educação, tornou-se imperativo do Estado brasileiro [governado federalmente por um branco]: indivíduos, família, sociedade, empresas, instituições filantrópicas, dentre outros, foram convocados a se envolverem atuando como parceiros do Estado nos projetos de inserção social pela educação (LOPES; RECH, 2013).

Contudo, quando investigam, historicamente, o desenvolvimento do direito à educação no Brasil, grande parte dos estudos não evidencia a presença da cor de pele/raça como elemento essencial de análise para compreensão das práticas do Estado na criação das políticas públicas. Desse modo, este ensaio ${ }^{3}$ tem como objetivo discorrer acerca da construção do direito à educação no Brasil, evidenciando como a presença de pessoas [com pele branca ${ }^{4}$ foi historicamente determinante

\footnotetext{
2 Ao longo do texto será utilizado o recurso de destaque da palavra branca, e suas variações, como estratégia de denunciar o modo como a questão da cor/raça sempre esteve presente nas disputas sociais no campo da educação no Brasil. Acredita-se que grande parte das análises histórico/científicas negam essa materialidade de cor e, consequentemente, mantêm operando uma produção de conhecimento supostamente a-racial (sem cor de pele ou de cor falsamente neutra ou universal). Ao ser utilizado o negrito como recurso de denúncia pela escrita, se tem como hipótese que a negação da cor/raça, nas diferentes esferas de produção de conhecimento, mantém operando um significativo branqueamento das análises sociais (nas ciências, nas políticas, nas práticas profissionais, nos discursos acadêmicos, na formação de estudantes, etc.) dificultando uma eficaz superação dos efeitos do escravismo no Brasil contemporâneo.
}

\footnotetext{
${ }^{3}$ A presente proposta integra pesquisas na área da Psicologia Social e Institucional de matriz pós-estruturalista, de base foucaultiana. Nelas, a produção de conhecimento reivindica uma epistemologia própria, já que não é contemplada pelas perspectivas tradicionalmente abordadas (HÜNING; SCISLESKI, 2018). Com isso, um dos aspectos de sua produção científica é a desnaturalização de elementos da história e do presente para a produção de pensamentos, e não de verdades forjadas. Destaca, assim, a construção de um conhecimento particular, política e historicamente localizado (ECKER, 2018).
}

\footnotetext{
${ }^{4}$ Reconhece-se a existência de diversos movimentos e representantes da luta social no campo da negritude e afirma-se a importância dos mesmos para o avanço na garantia de direitos da população negra, no campo da educação, ao longo da história
} 
na elaboração das políticas de educação do Brasil contemporâneo. Para isso, analisa as Constituições Federais brasileiras $(1824 ; 1891 ; 1934 ; 1937 ; 1946 ; 1967 ; 1988)$, em articulação com estudos sobre as especificidades sócio-históricas do Brasil. Através dos materiais, explicita a presença da cor/raça [branca] na formulação das políticas de educação e aponta alguns dos possíveis efeitos dessa branquitude no delineamento dos grupos raciais que acessaram a educação, enquanto direito, e como via de acesso ao poder.

\section{MARCAS [BRANCAS] NAS PRÁTICAS EDUCATIVAS: COROA PORTUGUESA E JESUÍTAS}

Entre 1500 a 1700, nos 200 anos que esboçam a emergência do Brasil Colonial, não havia projetos educativos formais; os sistemas escolares esboçavam-se incipientementes por toda a Europa. Por volta de 1500, a Coroa portuguesa [de pele branca] empreende o financiamento de navegações marítimas pelas Américas, com duas principais finalidades: expandir-se comercialmente e difundir a palavra de Deus através dos padres [brancos] católicos, cristãos (GALEANO, 2014). Nesse contexto, o acesso à educação era seleto da classe sacerdotal e da alta nobreza [primordialmente de cor de pele branca] que herdavam diretamente sua posição social, governando soberanamente por normas que prevaleciam sobre qualquer grupo social intermediário. Quando incidiam sobre outras pessoas para além dos soberanos, as práticas educacionais amparavam-se sob três principais objetivos: 1) Objetivo doutrinário: ensinar a religião e a prática cristã como base para condução de condutas; 2) Objetivo econômico e social: instituir o hábito do trabalho e de extração de riquezas, para monopólio dos soberanos [de pele branca], como princípio fundamental na formação das colônias brasileiras; 3) Objetivo político: utilizar os índios e negros convertidos/educados, como soldados ao fronte contra ataques dos que se opunham ao projeto colonizador [dos brancos] (SHIGUNOV NETO; MACIEL, 2008).

Não era um direito ou uma escolha dos escravos aprenderem a ler e a escrever. Submetidos à dominação, ameaças e frequentes assassinatos, índios e negros eram obrigados a aderir ao projeto colonizador. Havia padres jesuítas [de pele branca] que defendiam a liberdade dos escravos através dos preceitos que embasavam a Companhia de Jesus, mas não se opunham formalmente à escravatura, em virtude de sua situação diplomática frente à Coroa portuguesa (SHIGUNOV NETO; MACIEL, 2008). O apoio oficial da Coroa favorecia os padres jesuítas, amparando-os na sua missão catequizadora "com largas doações de terras e aplicações de rendimentos reais dotação de seus colégios" (AZEVEDO, 1976, p.36). Na educação da alta nobreza [de pele branca], os padres jesuítas auxiliaram na formação de sujeitos para a classe religiosa e para compor a administração política da Coroa, que resultava numa delimitação racial e religiosa em quem acessava os cargos de poder (AZEVEDO, 1976). A massiva intervenção pela educação jesuítica operou na homogeneização de grande parte dos povos locais, anulando ou afastando outros modos de vida que não fossem aqueles formatados ao projeto de colonização portuguesa [de pele branca], cristã, católica (ECKER, 2016).

brasileira. Contudo, neste texto, enfatizou-se uma leitura da história dando destaque para as pessoas de pele branca que se fizeram presentes nas disputas sociais dessa esfera. 
Com apoio da Coroa, as escolas dos jesuítas proliferaram no Brasil e, apenas entre 1556 a 1606, seus membros se multiplicam de mil para 13 (treze) mil. Sob o comando do padre Manuel da Nóbrega [de cor de pele branca], foram fundadas cinco escolas de instrução elementar (em São Vicente, São Paulo de Piratininga, Porto Seguro, Ilhéus e Espírito Santo) e três colégios (na Bahia, Pernambuco e Rio de Janeiro). O que se tem por registro é que a obra [branca e violenta] educacional dos jesuítas no país, mesmo com as limitações materiais, físicas e geográficas daquele período, impressionam por seu impacto social no país:

[...] foram fundadas 36 missões; escolas de ler e escrever em quase todas as povoações e aldeias; 25 residências dos jesuítas; 18 estabelecimentos de ensino secundário, entre colégios e seminários, nos principais pontos do Brasil, entre eles: Bahia, São Vicente, Rio de Janeiro, Olinda, Espírito Santo, São Luís, Ilhéus, Recife, Santos, Porto Seguro, Paranaguá, Alcântara, Vigia, Pará, Colônia do Sacramento, Florianópolis e Paraíba (SHIGUNOV NETO; MACIEL, 2008, p.186).

\section{Marcas [brancas] nas práticas educativas: anseios da Coroa portuguesa}

O desenvolvimento da educação na passagem do Brasil Colônia para o Brasil Império, entre 1700 e 1800, evidencia um contexto histórico de 100 anos produzido em meio a conturbações sociais, com intensas transformações políticas e econômicas. A instituição [principalmente pela violência] da língua portuguesa, da moral e dos costumes europeus e cristãos [de pele branca], havia tornado possível a produção de aldeias e esboços de metrópoles no país, pautadas pela centralidade da religião católica e da prática do trabalho, em grande parte de origem escravista, como forma de conduzir a população (ECKER, 2016).

Nesse processo, institui-se o Decreto-lei de 03 de setembro de 1759, de Marquês de Pombal [de pele branca], e o Rei D. José I [de pele branca] suspende as atividades educativas da Companhia de Jesus na Colônia brasileira. A expulsão dos jesuítas das terras brasileiras visava total abandono das antigas ações educacionais, propostas pela Companhia de Jesus, desejando-se criar novas intervenções condizentes com o cenário político e econômico (AZEVEDO, 1976). Entretanto, a condição sócio-histórica conturbada em torno de Portugal, impossibilitou a expansão de instituições educacionais:

[...] o que provocou um longo período (1759 a 1808) de quase desorganização e decadência da Educação na colônia. [...] a expulsão dos jesuítas em 1759 e a transplantação da corte portuguesa para o Brasil em 1808, abriu-se um parêntese de quase meio século, um largo hiatus que se caracteriza pela desorganização e decadência do ensino colonial. Nenhuma organização institucional veio, de fato, substituir a poderosa homogeneidade do sistema jesuítico [brancos], edificado em todo o litoral latifundiário, com ramificações pelas matas e pelo planalto, e cujos colégios e seminários forma, na Colônia, os grandes focos de irradiação da cultura [branca, cristã, católica] (AZEVEDO, 1976, p.61).

Concomitantemente aos conflitos que ocorriam em Portugal e os preparativos de transferência da Coroa para o Brasil, teremos na França de 1793, a emergência da Declaração dos Direitos do Homem e do Cidadão, emitida pela Convenção Nacional Francesa [homens de pele branca]. Esse documento, em contexto ocidental, é central para se compreender a instituição da educação como 
direito no ocidente. Através da Assembleia Francesa ele instituirá, pela primeira vez, a ideia da educação como ideal social, engendrando argumentos que integram noções sobre inteligência, social, público, progresso e cidadania: "[...] a sociedade deve favorecer com todo o seu poder o progresso da inteligência pública e colocar a instrução ao alcance de todos os cidadãos" (ASSEMBLEIA NACIONAL FRANCESA, 1793, Art $^{\circ}$. XXII).

A Declaração dos Direitos do Homem e do Cidadão estabelece uma série de argumentos que permitem circunscrever certo lugar à educação vinculada à noção de direito e, no Brasil, as propostas de Marquês de Pombal [branco] sobre a educação, potencializam-se quando aliadas aos argumentos instituídos pela Declaração do Homem e do Cidadão. Entretanto, negras e negros, no país, não eram considerados cidadãos, o que remete a um recorte muito específico de população [de pele branca] que as propostas de Marques contemplariam. De modo [racialmente branco] seletivo, a educação estava adquirindo nessa época, de forma não apenas estratégica, um tom profético e totalizador: via para a salvação, via para o progresso individual e, portanto, via, também, para o progresso social (BOTO, 1996).

\section{MARCAS [BRANCAS] NAS PRÁTICAS EDUCATIVAS: LIBERAIS E CONSERVADORES}

As sistemáticas incidências nos corpos dos povos destituídos de poder, como negros (as) e indígenas, haviam possibilitado homogeneizar a população, produzindo certa unicidade linguística, religiosa [católica] e ideológica [branquitude, permeada pela lógica econômica branca-cristã-burguesa]. Síncrono ao desenvolvimento de uma cultura urbanizadora, entre os anos1800 e 1900, a educação e o trabalho tornavam-se base da produção de uma metrópole, definindo contornos no desejo da Coroa Portuguesa [brancos] de tornar o Brasil um país independente. Contudo, o modelo educacional republicano adotado em países vizinhos não era algo desejado em terras brasileiras (ECKER, 2016), pois produzir liberdade e democracia no Brasil, daquela época, ameaçaria um sistema escravocrata, de divisões sociais definidas e desiguais, que sustentava a socioeconomia. Assim, atrasar a instrução dos povos, mantendo-os de certa forma ignorantes aos processos sociais, permitia abrandar a expansão do "espírito nacionalista que começava a aflorar" (SHIGUNOV NETO; MACIEL, 2008, 272).

A estratégia proposta pela aliança política entre representantes da soberania [brancos], liberais [brancos] e conservadores [brancos] será a de instituir um sistema educacional onde as funções e valores de cada classe social ficassem bem definidos: mantendo as divisões baseadas no poder econômico [dos brancos] e perpetuando a gestão de governo transmitida pela herança [de brancos para brancos] organizada em torno das alianças familiares consanguíneas (MACIEL; SHIGUNOV NETO, 2006, p.472). Houve, então, a fundação de dois tipos principais de escola pública: uma para os grupos sociais menos abastados, em nível primário, que poderiam vir a oferecer serviços à nobreza [branca] e outra voltada aos filhos de nobres [brancos], em nível primário e secundário, que exerceriam cargos políticos ou funções sociais através de sua profissão. Neste período, inclusive, já é possível encontrar ensinos particulares para a classe burguesa [branca], que obtinham benefícios de apoio do Estado [brancos no poder sendo apoiados por brancos que representavam o Estado] (MACIEL; SHIGUNOV NETO, 2006, p.472). 
Fortalecer a classe nobre burguesa [branca], em todos os níveis de ensino, para depois pensar em expandir o ensino popular. Com a vinda de D. João VI [de pele branca] ao Brasil, foram inauguradas diversas instituições educativas e culturais. Surgiram cursos superiores de Direito, Engenharia e Medicina. Dentre a fundação de várias escolas e academias de nível superior, cabe destacar que grande parte dos cursos ainda eram iniciantes em sua organização e estrutura, pois se focavam apenas no processo de profissionalização das classes burguesas [brancos], que tinham acesso a todos os níveis de ensino (FREITAG, 1986). Nesse contexto, ocorre a Proclamação da Independência e promulgação da Constituição Política do Império do Brazil, instituída pelo Imperador Dom Pedro I [de pele branca], em que a educação é afirmada como dever do Império, no que se referia à garantia de "Direitos Civis, e Politicos dos Cidadãos Brazileiros" (BRASIL, 1824, Art".179). Entretanto, a referência de cidadão era delimitada e específica: de composição majoritariamente masculina [de pele branca], o poder político e econômico da época se centrava nas mãos dos fazendeiros [brancos], sendo a metade da população brasileira composta por seus escravos. Estima-se, nesse momento, que o Rio de Janeiro, Minas e São Paulo somavam, aproximadamente, 386 mil escravos. Bahia, Pernambuco e Maranhão detinham, nesse mesmo período, cerca de 484 mil (COSTA, 2007).

$\mathrm{Na}$ Constituição de 1824 não havia a ideia de democracia e o regime do Estado era privativo ao Imperador [de pele branca]: "Art. 99. A Pessoa do Imperador é inviolavel, e Sagrada: Elle não está sujeito à responsabilidade alguma". A religião católica [que representava em sua maioria os brancos] tornou-se doutrina oficial do Estado: "Art. 5. A Religião Catholica Apostolica Romana continuará a ser a Religião do Imperio" e a propriedade privada tornou-se Direito Civil e Político inviolável "dos Cidadãos [brancos] Brazileiros" (BRASIL, 1824, Art'.179). Destaca-se que a educação, nesse período, ainda não era algo lucrável em torno da população como um todo, portanto, o que havia de se manter operando era a economia canavieira, o ciclo da mineração, o algodão, o açúcar e o café, fontes de riqueza extraídas pelo uso de um sistema escravagista (FERRARO, 2010). Sistema escravagista que justificava a intenção de manter as práticas educativas restritas a um seleto [branco] grupo.

Nessa lógica, o Decreto $n^{\circ} 3.029$, em meados de 1881, formulado pelo Deputado Antônio Saraiva [de pele branca], fortalece a aliança entre as práticas governamentais e a educação, que delimitavam quem poderia ser cidadão reconhecido. Fortalecendo a burguesia [grande parte de pele branca], a Lei Saraiva afirmou a proibição do voto a todos aqueles sujeitos que eram analfabetos, ou seja, privou da participação política todos aqueles que não haviam sido submetidos a uma ação educacional do ler e do escrever. A Lei, instituída em um momento estratégico, onde apenas $10 \%$ da população teria total direito ao voto [homens brancos], é elaborada por um grupo político elitizado [branco] que não se preocupava com o voto em si, mas sim, com a exclusão do povo nos processos de participação política (FERRARO, 2010). A educação popular, universal, gratuita, de qualidade e oferecida nos diferentes níveis de ensino, não interessava ao tipo de sociedade que se constituíra no Brasil dessa época (ECKER, 2016).

Assim, as iniciativas de governo pela educação, oficializadas com a Constituição de 1891, que instaura a República dos Estados Unidos do Brasil, voltaram-se apenas ao investimento no ensino superior (BRASIL, 1891), dos que compunham o Império [brancos] e ao ensino primário e secundário, em torno dos membros da Corte [de pele branca]. Ao mesmo tempo, porém, em que a Constituição e a 
Lei Saraiva produziam um efeito tranquilizador nas elites [brancas] brasileiras, especialmente àquelas ligadas aos interesses agrários, os movimentos de reivindicação do direito à escola foram acontecendo (AZEVEDO, 1976). Esses movimentos, tensionados pela exclusão de grande parte do povo do voto, expressam o que se poderia ser chamado de certa 'vontade de educação', vontade de ser educado. Essa positividade se afirma, desde a produção na população da vontade de ser educado, já que agora ela identifica na educação um modo de se incluir nos processos políticos do país e de ascender socialmente, quanto nos governantes [brancos], que passam a pensar sobre o acesso que é dado ao povo à participação política (também como forma estratégica de que, em parceria com o povo, eles visassem conseguir remover do poder as chapas de oposição) (OLIVEIRA, 2004).

\section{MARCAS [BRANCAS] NAS PRÁTICAS EDUCATIVAS: POLÍTICOS E INTELECTUAIS}

A recente instituição da República brasileira [por um homem branco], acompanhava a construção de uma educação, que se constituía como disciplina no país entre os anos de 1900 a 1988. Militares, burgueses oriundos da indústria emergente, sujeitos das novas camadas médias, imigrantes e intelectuais [grupos em que predominavam a presença de pessoas de pele branca], integravam agora as tramas de poder que se produziam no Brasil. Nesse momento, não havia uma política nacional de educação acessível a todas as diferentes cores de pele. O que se encontrava, ao fim do Império, era um número baixo de escolas primárias com, em média, 250 mil alunos, em um país com cerca de 14 milhões de habitantes (dos quais $85 \%$ eram analfabetos), liceus provinciais nas capitais, colégios particulares [para brancos], nas principais cidades (de cunho religiosos, católicos), alguns cursos normais e cursos superiores [para brancos] (CARVALHO, 2010).

Com a inexistência de uma política educacional unificada e, ao mesmo tempo, a presença de uma multiplicidade de interesses das elites [brancas], emergem diversas propostas políticas [formuladas por brancos ou com o nome de pessoas brancas], que conciliavam os interesses dos variados grupos que ocupavam o poder, sendo algumas dessas propostas 5 : o projeto político de Benjamin Constant [branco]; o Código Epitácio Pessoa [branco]; a Lei Orgânica Rivadávia Corrêa [branco] (RIBEIRO, 1998); a reforma Carlos Maximiliano [branco]; a reforma Rocha Vaz [branco], dentre outras (OLIVEIRA, 2004).

Esses e outros projetos eram interessantes porque conciliavam numa mesma formação de Estado cinco questões: 1) a emergência de um ensino de inspiração liberal-burguês, desejado pela nova classe intermediária [grande parte, pessoas de pele branca], que estava ligada ao comércio e se concentrava na zona urbana; 2) manutenção de valores e padrões da velha mentalidade aristocráticarural [brancos], que se mantinham como elite e ansiavam por conservar suas tradições do bem falar; 3 ) ampliação da oferta de ensino popular, que acalmava as reivindicações e representava um custo menor às elites [brancas], sem precisar que se alterassem a distribuição de renda e as relações de poder; 4) perpetuação, agora com funcionamento relativamente autônomo, da iniciativa particular sustentada pela Igreja [brancos]; e, por fim, 5) mantinha instituída a ideologia ilusória da ascensão

${ }^{5}$ Além de serem formuladas por brancos, todas as propostas tem nomes de homens brancos. 
social pela escolarização (OLIVEIRA, 2004). Seguindo esse raciocínio, poderia se acrescentar a imposição de um sexto interesse: 6) Presença dominante da cor/raça branca na condução dessas intervenções.

No campo dos intelectuais [grande parte de pele branca], as propostas de modificações nas políticas de educação no Brasil, terão como base a crítica às desigualdades e privilégios [privilégios dos brancos, mas sem nomear a cor deles]. Contudo, de um modo ainda elitista, inspirados nos movimentos internacionais, especialmente da pedagogia pragmática da Escola Nova, retomarão as ideias difundidas no contexto europeu e americano sobre a educação, como via para o progresso social. Característico do modo de pensar liberal-burguês [branco], a ideia de progresso pela educação estava associada à implementação de um ensino laico, democrático, gratuito e obrigatório (RIBEIRO, 1993). Nesse viés elitista [branco] de proposições, emergirão diversas iniciativas como, por exemplo, as seguintes: 1) Sampaio Dória [de cor de pele branca], propôs a redução do primário de quatro para dois anos, afirmou a obrigatoriedade e gratuidade do ensino em São Paulo e reduziu a jornada escolar (DÓRIA, 1923); 2) na perspectiva [branca] conservadora higienista-educacional, a Ação Integralista Brasileira [AIB], composta por membros [brancos] de uma corrente política elitista e autoritária, propunha a educação integral de determinada parcela da população, vinculada à ideia de controle social e hierarquização das massas; 3) na perspectiva liberal, o intelectual Anísio Teixeira [homem de cor de pele branca], um dos autores do Manifesto dos Pioneiros da Educação Nova (1932), propunha a educação integral do povo como um percurso necessário para o desenvolvimento da democracia e da economia (CAVALIERE, 2010).

Destaca-se o Manifesto [escrito em sua maioria por brancos], que teve grande repercussão na época e referia-se como alvo da educação pública uma população específica: o povo e as massas populares.

d) O problema dos melhores [como foram brancos que escreverem, estaria relacionado o "ser branco" com o ser "melhor"?]

De fato, a Universidade, que se encontra no ápice de todas as instituições educativas [que apenas brancos acessam], está destinada, nas sociedades modernas a desenvolver um papel cada vez mais importante na formação das elites de pensadores [brancos], sábios [brancos], cientistas [brancos], técnicos [brancos], e educadores [brancos], de que elas precisam para o estudo e solução de suas questões científicas, morais, intelectuais, políticas e econômicas. Se o problema fundamental das democracias é a educação das massaspopulares, os melhores e os mais capazes, por seleção, devem formar o vértice de uma pirâmide de base imensa (AZEVEDO et al, 2006)

Compreende-se, historicamente, a contribuição que o Manifesto dos Pioneiros teve na formulação de políticas públicas de educação no Brasil, entretanto, é necessário apontar para [a branquitude] o viés hierarquizado de classe social e, indiretamente, de raça, que estava presente nas suas proposições. Será, inclusive, influenciada pelas proposições de políticos liberais [brancos] e conservadores [brancos], assim como as dos intelectuais [em sua maioria de pele branca], que teremos na Constituição Federal de 1934 [promulgada durante o regimento de um presidente branco], pela primeira vez, a ideia de educação como direito de todos: 
A educação é direito de todos e deve ser ministrada, pela família e pelos Poderes Públicos, cumprindo a estes proporcioná-la a brasileiros e a estrangeiros domiciliados no País, de modo que possibilite eficientes fatores da vida moral e econômica da Nação, e desenvolva num espírito brasileiro a consciência da solidariedade humana (BRASIL, 1934).

O discurso na Constituição de 1934, 'direito de todos', invisibiliza e neutraliza, pela jurisdição, toda uma sociedade de acesso desigual em torno da cor de pele/raça, que havia sido forjada, historicamente, nas disputas sociais em torno da educação. Ao mesmo tempo, concilia e unifica a questão da obrigatoriedade escolar, exigida pelos movimentos sociais e partidos liberais [na maioria brancos] que, como demonstra o fragmento acima, ficou a cargo de ser ministrada pela família e pelo Poder Público. Cabe destacar que a preocupação dos intelectuais [brancos] com a obrigatoriedade, se referia ao nível público de ensino, o qual focava na gestão das massas e das camadas populares [possivelmente os não brancos]. É nesse recorte populacional que as discussões incidiam e, inclusive, será nesse período que emergirão diversas propostas de educação integral [manter os não brancos o dia todo na escola] (ECKER, 2016).

No contexto de Segunda Guerra Mundial, haverá nas políticas da educação no Brasil certa aproximação com os ideais Estadunidenses. Nesse período serão estabelecidos acordos, congregações e alianças, assim como a criação da OCIAA [Office of the Coordinator of Inter-american Affairs] ${ }^{6}$ [de membros brancos], permitindo introduzir certa americanização no Brasil, na cultura e educação, principalmente em torno da organização do ensino de nível técnico brasileiro (RABELO, 2009). Nesta época houve forte investimento em torno de ações que formassem futuros operários [aqueles que talvez não fossem brancos], para a indústria e, tal investimento, tornou possível fazer emergir o Serviço Nacional de Aprendizagem Industrial [SENAI] e o Serviço Nacional de Aprendizagem Comercial [SENAC], ensinos de nível técnico voltados à parcela mais pobre da população (PIANA, 2009).

Com a derrubada de Getúlio Vargas do poder [de cor de pele branca e substituído por outro homem de pele branca], por volta de 1945, o Brasil passou por um período de democratização. Em torno da educação, esse movimento marcava certo conflito entre defensores da escola pública, em contraponto aos que afirmavam as escolas particulares (RIBEIRO, 1993). Na Constituição de 1946, a educação, enquanto dever do Estado, aparecerá no Art $^{\circ}$. 171, mantendo a regulamentação da Constituição anterior, referindo que "Os Estados e o Distrito Federal organizarão os seus sistemas de ensino". Contudo, não foi instituído ser dever dos Estados ou da Federação garantir a existência de vagas, acesso ou permanência, ou seja, a educação estava livre à iniciativa privada [ gerida em grande parte por brancos] sem a oposição direta do governo federal [representado, em sua maioria, por homens brancos] (BRASIL, 1946).

Sob justificativa de democratização, ocorreu ênfase de investimentos no ensino superior brasileiro [historicamente direcionado à população de elite e branca], com o governo estabelecendo uma série de acordos entre o Ministério da Educação e Cultura [MEC] e a Agency for International Development [AID] (RIBEIRO, 1993). Conhecidos como acordos MEC-USAID, tinham, como intenção

\footnotetext{
6 Departamento norte-americano que tinha como objetivo estabelecer relações entre as duas nações.
} 
inicial, privatizar as escolas públicas, implantando um modelo norte americano nas universidades brasileiras e, depois, previam a contratação de assessores americanos [brancos] que auxiliariam nas reformas da educação pública em todos os níveis de ensino (CONFEDERAÇÃO NACIONAL DOS TRABALHADORES EM EDUCAÇÃO, 2015). Os acordos internacionais dessa época, em torno da educação, expandiram a economia do país. Com a regularização e estratificação das ações governamentais do MEC, a educação ampliou seus objetos de intervenção e desmembrou um saldo de dotação orçamentária, destinado unicamente ao seu Ministério (BRASIL, 1953) [promulgada por um presidente branco]. Na Constituição de 1967 [escrita pelo ministro da Justiça e por juristas brancos], a educação pública ampliou sua conexão com o apoio das iniciativas privadas de ensino, através do amparo técnico e financeiro dos Poderes Públicos, incluindo a oferta de bolsas de estudos (BRASIL, 1967).

Com a época de ditadura civil-militar, entre a década de 1960 e 1980, oficializam-se vínculos entre as políticas de educação ${ }^{7}$ com a economia, o mercado internacional e o mercado local, sob o argumento de desenvolvimento do Brasil como Estado, por parte de representantes da federação [em grande parte, homens brancos]. Instituir uma política Estatal mais consistente, que operasse sobre toda a vastidão da problemática educacional e abrangesse a população como um todo, voltava a atenção do governo para a criação de um Ministério específico. Em 15 de março de 1985, pelo Decreto $\mathrm{n}^{\circ} .91 .144$ (BRASIL, 1985) [promulgado por um vice-presidente da república branco], houve um novo desmembramento e o Ministério da Educação e Cultura se difundiu em dois Ministérios específicos e autônomos [gerenciados por ministros de cor de pele branca]. Esse desmembramento abre campos de possibilidade para a instituição da educação como Direito Social na Constituição de 1988 [promulgada por um presidente branco]. Afirmando a educação como "direito de todos" (BRASIL, 1988, Art.205), novamente, diluía-se, discursivamente, na palavra 'todos', uma intensa desigualdade racial que fora construída com o auxílio das políticas de educação na história do Brasil que, por séculos, não possibilitou o acesso aos brancos e negros de modo igualitário e com equidade.

\section{MARCAS [BRANCAS] DO ESCRAVISMO NAS POLÍTICAS PÚBLICAS DE EDUCAÇÃO NO BRASIL CONTEMPORÂNEO}

O direito à educação no Brasil, pós-ditadura, emerge discursivamente, na Constituição Federal de 1988, como 'de todos'. Contudo, com 388 anos de escravismo, sustentado por um Estado que teve nos seus cargos de gestão uma parcela prioritariamente branca e masculina, esse direito chega na contemporaneidade com marcas [brancas] de privilégios. Na construção do Brasil, as ações educativas tiveram práticas sustentadas por violência e dominação [soberanos e padres brancos]. Através da intervenção de brancos, se tornou possível a criação de aldeias educadoras, centros irradiadores de povoamento de molde branco-burguês-católico, esboço das futuras metrópoles. Homogeneizou-se a diversidade de povos e costumes, por práticas educativas que anularam aspectos raciais referentes à

\footnotetext{
${ }^{7}$ Estima-se que hajam, de acordo com dados do Instituto Nacional de Estudos e Pesquisas Educacionais Anísio Teixeira [INEP], 976 escolas públicas brasileiras com nomes de envolvidos com o período da Ditadura (CNTE, 2015).
} 
cultura, religião e linguagem. Inicialmente, pela conexão entre religião católica e o trabalho, para depois instituir a coexistência de outros projetos educacionais, a educação, por séculos, serviu como ferramenta de fortalecimento de um molde [branco] específico de Estado, correlacionado aos interesses das elites [brancas] do país.

Um sistema educacional, em meados do século XIX, com funções definidas por classe social, segregava por raça, mesmo que essa não fosse a justificativa. O posterior desenvolvimento de uma educação pública apenas de nível superior [para os brancos], legitimou a estratégia de fortalecimento da classe [branca] nobre burguesa. Assim, os argumentos demagogicamente democráticos sobre a construção de uma educação pública no Brasil, universal e gratuita, por muito contribuíram para a afirmação de certo monopólio político e racial: defesa da propriedade [dos brancos], legalização de projetos elitistas [em grande parte propostos por homens brancos] e consequente manutenção da fragilidade de direitos da população negra. Diversos desses projetos mantiveram a elite [branca] no cerne da posse e do acesso à formação de nível superior. Mesmo que o investimento no ensino básico gratuito tenha sido pouco, fora suficiente para, na metade do século $X X$, acalmar as reivindicações populares [dos não brancos] e ter um menor custo às elites [brancas] sem ser preciso que se alterassem a distribuição de renda ou as relações desiguais de poder e de raça.

A histórica exacerbação de discursos sobre o ensino público [a gestão dos não brancos], antes da Constituição de 1988, em sobreposição aos mínimos debates sobre alterações no ensino privado e popularização do acesso na iniciativa privada/particular, permitiu a perpetuação do monopólio da população [branca], nas diferentes esferas do ensino. Monopólio mantido, também, pelo livre funcionamento das instituições financiadas pela elite [brancos] e pela Igreja [brancos], assim como, com auxilio da mínima intervenção do Estado para democratizar as instituições privadas pré e pós1988. Por séculos, a ideia de público e privado sequer existia, já que a educação se operacionalizava como a garantia apenas dos desejos privativos do soberano [branco], com apoio e interesse da Igreja [brancos]. Assim, as ações educativas, desde o período colonial, compuseram-se como estratégias essenciais na manutenção de hierarquias raciais e sociais no Brasil, diferenciando soberanos [brancos] e escravos, burguesia [brancos] e camadas populares, elite [brancos] e população. Diferenciação que produziu acessos desiguais, seja através do modo como os serviços eram dispostos e pensados, seja pelo investimento que se fazia, ou não, a específicos níveis educacionais. Seletividade que, mesmo não oficializada, tinha cunho escancaradamente racial.

Através da presente análise, fica evidenciado como, desde o período colonial, soberanos, religiosos, senhores de engenho, fazendeiros, políticos liberais, conservadores, burgueses emergentes da indústria, intelectuais, militares, representantes de instituições públicas, privadas, movimentos da sociedade organizada, intelectuais do ensino superior (público e privado) e de instituições científicas presentificaram a branquitude, sobretudo de homens brancos, frente aos cargos de construção da educação como direito no país. Ações educativas, Constituições Federais, Leis, Projetos de Lei, Decretos, articulações políticas, acadêmicas e ideológicas, foram construindo um sistema forjado para proteger grupos [brancos] no poder, resultando na contenção racial contemporânea dos(as) negros(as), no que se refere à emancipação e construção de suas cidadanias. Devido a toda uma aparelhagem educacional que se constituiu [formulada por brancos], sob a falácia da educação como 'direito de 
todos', as ações educacionais ao longo da história do Brasil auxiliaram na organização, gestão e validação de uma intensa estrutura sócio-racial desigual, que constituiu a nação pela esfera da educação. Assim, a partir da presente análise, infere-se que as ações de inclusão pós-Constituição de 1988, como as cotas raciais, não serão suficientes para sobrepor ou superar a intensa estrutura desigual que historicamente marcou [brancamente] o Brasil contemporâneo.

Desenvolvendo estratégias sempre mais sofisticadas, [brancos/as] ocupam serviços privados/particulares de educação, nos mais variados níveis de ensino no país, protegendo seus privilégios históricos disfarçados sob o discurso de que os direitos seriam "de todos". Perpetuam, assim, a garantia de posições políticas, cargos de níveis superiores, acesso a empresas privadas e/ou familiares, assim como, ocupando os mais variados cargos de gestão do país, sob a lógica da herança e/ou do auto-investimento econômico, com apoio entre semelhantes. Com proteção do Estado que, no campo da educação, prevê, pela Constituição de 1988, a livre operacionalidade de instâncias privadas/particulares, pouco se incide sobre os direitos das pessoas de pele branca, que acessam essas instituições. Marca-se, assim, um legado do escravismo no Brasil contemporâneo que perpetua, pela jurisdição brasileira [atualmente presidida e regulada por um homem branco], desigualdades sócio-raciais e políticas sem a devida equidade.

\section{REFERÊNCIAS}

1. ASSEMBLEIA NACIONAL FRANCESA. Declaração dos Direitos do Homem e do Cidadão. Biblioteca Virtual de Direitos Humanos, Universidade de São Paulo - USP, São Paulo - SP, 1793.

2. AZEVEDO, Fernando de. A cultura brasileira. Parte 3: A transmissão da cultura, 5.ed. São Paulo: Melhoramentos/INL, 1976.

3. BOTO, Carlota. A escola do homem novo: entre o lluminismo e a Revolução Francesa. São Paulo: Editora da Universidade Estadual Paulista, 1996.

4. BRASIL. Constituição Politica do Imperio do Brazil, de 25 de março de 1824. Brasília - DF, 1824. Disponível em: <http://www.planalto.gov.br/ccivil_03/constituicao/constituicao24.htm> Acesso em: 07 jun. de 2019.

5. BRASIL. Constituição da República dos Estados Unidos do Brasil, de 24 de fevereiro de 1891. Brasília - DF, 1891. Disponível em: <http://www.planalto.gov.br/ccivil_03/constituicao/constituicao 91.htm> Acesso em: 07 jun. de 2019.

6. BRASIL. Constituição da República dos Estados Unidos do Brasil, de 16 de julho de 1934. Brasília - DF, 1934. Disponível em: <http://www.planalto.gov.br/ccivil_03/constituicao/constituicao34.htm> Acesso em: 07 jun. de 2019. 
7. BRASIL. Constituição dos Estados Unidos do Brasil, de 18 de setembro de 1946. Brasília - DF, 1946. Disponível em: <http://www.planalto.gov.br/ccivil_03/constituicao/constituicao46.htm> Acesso em: 07 jun. de 2019.

BRASIL. Lei $\mathrm{n}^{\circ}$. 1.920, de 25 de julho de 1953. Brasília - DF, 1953. Disponível em: <http://www.planalto.gov.br/ccivil_03/leis/1950-1969/L1920.htm> Acesso em: 07 jun. de 2019.

9. BRASIL. Constituição da República Federativa do Brasil de 1967. Brasília - DF, 1967. Disponível em: <www.planalto.gov.br/ccivil_03/constituicao/Constituicao67EMC69.htm\#novaredação> Acesso em: 07 jun. de 2019.

BRASIL. Decreto $n^{\circ}$. 91.144, de 15 de Março de 1985. Brasília - DF, 1985. Disponível em: <http://www2. camara.leg.br/legin/fed/decret/1980-1987/decreto-91144-15-marco-1985-441406publicacaooriginal-1-pe.html> Acesso em: 07 jun. de 2019.

BRASIL. Constituição da República Federativa do Brasil de 1988. Brasília - DF, 1988. Disponível em: <http://www.planalto.gov.br/ccivil_03/constituicao/constituicao.htm> Acesso em: 07 jun. de 2019.

BRASIL. Fundo Nacional de Desenvolvimento da Educação (FNDE). Programas. Brasília - DF, 2015. Disponível em: <http://www.fnde.gov.br/> Acesso em: 07 jun. de 2019.

13. CARVALHO, José Murilo de. A Construção da Ordem.a elite política; Teatro das Sombras: a política imperial. 5a edição, Rio de Janeiro: Civilização Brasileira, 2010.

CONFEDERAÇÃO NACIONAL DOS TRABALHADORES EM EDUCAÇÃO. O retrocesso na educação. CNTE, 2015. Disponível em: <http://ditaduranuncamais.cnte.org.br/o-retrocesso-naeducacao/> Acesso em: 07 jun. de 2019.

COSTA, Emília Viotti da. Da Monarquia à República: momentos decisivos. 8 ed. ver. Ed. ampl. São Paulo: Fundação Editora UNESP, 2007. CURY, Carlos Roberto Jamil. Estado e políticas de financiamento em educação. Educ. Soc., Campinas, vol. 28, n. 100 - Especial, p. 831-855, out. 2007. sobre o direito à educação no Brasil. 114f. Dissertação (Mestrado em Psicologia Social e Institucional) - UFRGS, Porto Alegre. Disponível em: <http://hdl.handle.net/10183/140998> Acesso em: 07 jun. de 2019. 
ECKER, Daniel Dall'Igna. Direitos Sociais e Acompanhamento Terapêutico: problematizações através de desenhos. Aurora: revista de arte, mídia e política, São Paulo, v.11, n.32, p. 95-109, jun.-set., 2018. Disponível em: <http://revistas.pucsp.br/index.php/aurora/article/view/31984/26874> Acesso em: 07 jun. de 2019.

FERRARO, Alceu Ravanello. Brasil: liberalismo, café, escola e voto (1878-1881). Educação em Revista, 26(3), 219-248, 2010. Disponível em: <http://dx.doi.org/10.1590/S0102-469820100003000 11> Acesso em: 07 jun. de 2019.

FREITAG, Bárbara. Escola, estado e sociedade. 6.ed. rev. São Paulo: Moraes, 1986.

GALEANO, Eduardo. As veias abertas da América Latina. Porto Alegre, RS: L\&PM, 2014.

HÜNING, Simone Maria; SCISLESKI, Andrea Cristina Coelho. Ressonâncias de uma epistemologia foucaultiana em psicologia social. Psicologia \& Sociedade, 30, e170632. Epub 03 de dezembro de 2018. Disponível em: <https://dx.doi.org/10.1590/1807-0310/2018v30170632> Acesso em: 07 jun. de 2019.

LOPES, Maura Corcini; RECH, Tatiana Luiza. Inclusão, biopolítica e educação. Educação (Porto Alegre, impresso), v. 36, n. 2, p. 210-219, maio/ago. 2013.

24. MACIEL, Lizete Shizue Bomura; SHIGUNOV NETO, Alexandre. A educação brasileira no período pombalino: uma análise histórica das reformas pombalinas do ensino. Educação e Pesquisa, 32(3), 2006, p.472. Disponível em: <http://dx.doi.org/10.1590/S1517-97022006000300003> Acesso em: 07 jun. de 2019.

OLIVEIRA, Marcos Marques de. As Origens da Educação no Brasil: da hegemonia católica às primeiras tentativas de organização do ensino. Ensaio: aval. pol. públ. Educ., Rio de Janeiro, v.12, n.45, p. 945-958, out./dez. 2004. Disponível em: <http://dx.doi.org/10.1590/S0104$40362004000400003>$ Acesso em: 07 jun. de 2019.

SHIGUNOV NETO, Alexandre; MACIEL, Lizete Shizue Bomura. O ensino jesuítico no período colonial brasileiro: algumas discussões. Educar em Revista, (31), 169-189, 2008. Disponível em: <http://dx.doi.org/10.1590/S0104-40602008000100011> Acesso em: 07 jun. de 2019. 


\section{Daniel Dall'Igna Ecker}

Psicólogo, Mestre em Psicologia Social e Institucional (UFRGS/2016) pela linha de pesquisa "Políticas Públicas e Produção de Subjetividade", com período sanduíche na Universidade Federal de Alagoas (UFAL/2015) na linha de Pesquisa "Processos Psicossociais". Doutorando na UFRGS em Psicologia Social e Institucional (bolsista CAPES) pela linha de Pesquisa "Clínica, Subjetividade e Política", com período sanduíche na Universidade Federal de Santa Catarina (UFSC/2018-2019) no Laboratório de Psicanálise, Processos criativos e Interações Políticas (LAPCIP).

\section{Como citar este documento:}

ECKER, Daniel Dall'Igna. Marcas [brancas] do escravismo nas políticas públicas de educação no Brasil contemporâneo. Reflexão e Ação, Santa Cruz do Sul, v. 27, n. 3, p. 160-174, out. 2019. ISSN 19829949. Disponível em: <https://online.unisc.br/seer/index.php/reflex/article/view/13623>. Acesso em: . doi:https://doi.org/10.17058/rea.v27i3.13623. 